\title{
Magnitude of the Paper-Deterioration Problem As Measured by a National Union Catalog Sample
}

The deterioration of paper has worried librarians for many years, and evidence that the situation is even worse than had been feared was supplied in 1959 when the Council on Library Resources sponsored studies on the permanence of book paper. Careful tests of the physical condition of 500 typical nonfiction books printed in the United States between 1900 and 1949 supported the conclusion that "it seems probable that most library books printed in the first half of the twentieth century will be in an unusable condition in the next century."1

During 1960 the Association of Research Libraries appointed a Committee on the Preservation of Research Library Materials under the chairmanship of Douglas W. Bryant of the Harvard University Library, and this committee has been investigating various aspects of the problem. One of the most obvious but also most difficult questions that has confronted it relates to the magnitude of the program that would be required to preserve research materials. It seemed desirable, as a first step, to try to determine how many different books are in American research libraries, and how many of these were printed since 1870 when the "poor-paper era" began.

Consequently a grant was obtained from the Council on Library Resources to enable the committee to retain the Research Triangle Institute of Durham, North Carolina, to draw and analyze a

1 Deterioration of Book Stock; Causes and Remedies. Two Studies on the Permanence of Book Paper, conducted by W. J. Barrow. Edited by Randolph W. Church (Richmond: The Virginia State Library, 1959) p. 16. sample from the National Union Catalog. It should be emphasized that all figures reported below refer only to books represented in the National Union Catalog, and do not include serial publications.

As copies of the Revised Final Report on the Sample of Cards from the Union Card Catalog, Library of Congress are available free of charge from Mr. Bryant, details of the sampling procedure will not be given here. The Main File of the Catalog was covered, as well as the Supplemental, Current, Slavic, Hebraic, Chinese, and Japanese sections; but cards for 1952-1955 were not included because they had been withdrawn at the time for reproduction. The sample consisted of 952 cards, of which 735 were for book titles; the remaining 217 were analytics, added entries, cross references, entries for manuscripts, etc.

The total number of cards in the National Union Catalog was estimated to be $15,330,800$. The number of different book titles represented was $10,493,300$ or, since the average number of volumes per title was 1.37 , approximately $14,376,000$ volumes. Of the titles, slightly more than 58 per cent $(6,099,800)$ were reported by a single library, but heavy duplication of holdings for some of the others brought the average to 2.35 holdings reported per title.

The average number of pages per title was estimated at 285.8965 , so the number of pages represented by all book titles in the catalog was estimated at $2,999,998,000$. It was further estimated (Continued on page 543) 
Paper Deterioration . . .

(Continued from page 499)

that 73.05 per cent of the titles $(7,665$,$800)$ and 57.34 per cent of the pages $(1,720,570,000)$ were printed since 1869 . Foreign imprints accounted for 65.72 per cent of the titles and 56.2 per cent of the total pages. A breakdown by decade of publication was made, as well as one by country of publication, but the number of items in each category is too small to provide estimates deserving of much confidence.

From the standpoint of preservation, the magnitude of one phase of the problem has been indicated more clearly than before by the estimate that books (not serials) printed since 1870 and represented in the National Union Catalog contain approximately one and threequarter billion pages.-Edwin E. Williams.

\section{OTTO HARRASSOWITZ Library Agency WIESBADEN - GERMANY}

Direct service on all German language books and periodicals

$*$

Orders and inquiries are invited on both new and out-of-print material $*$

Farmington Plan agent for West and East Germany

$*$

For economy, speed, and accuracy you may rely upon your

German agent

OTTO HARRASSOWITZ

\section{CUSHING-MALLOY, INC. 1350 North Main Street $\quad$ P.O. Box I187 Ann Arbor, Michigan}

\section{Printers of ACRL Monographs}

L I T H O P R I N T E R S

Known for

QUALITY-ECONOMY-SERVICE

Let us quote on your next printing 